\title{
Strain Analysis of the Nuozhadu High Rockfill Dam during Initial Impoundment
}

\author{
Xiaolong $\mathrm{Lv}^{1,2}$ and Shichun $\mathrm{Chi} \mathbb{D}^{1,2}$ \\ ${ }^{1}$ State Key Laboratory of Coastal and Offshore Engineering, Dalian University of Technology, Dalian, Liaoning 116024, China \\ ${ }^{2}$ Institute of Earthquake Engineering, Faculty of Infrastructure Engineering, Dalian University of Technology, Dalian, \\ Liaoning 116024, China
}

Correspondence should be addressed to Shichun Chi; schchi@dlut.edu.cn

Received 18 May 2018; Revised 28 June 2018; Accepted 24 July 2018; Published 30 July 2018

Academic Editor: Mohammad A. Hariri-Ardebili

Copyright (c) 2018 Xiaolong Lv and Shichun Chi. This is an open access article distributed under the Creative Commons Attribution License, which permits unrestricted use, distribution, and reproduction in any medium, provided the original work is properly cited.

\begin{abstract}
The safety of rockfill dams during initial impoundment has always been an issue of interest for regulatory agencies. Specifically, it is necessary to identify potential tensile strain zones and shear strain concentration zones in which cracks may form. In this paper, a meshless smoothing method is proposed to construct the strain field of a prototype dam based on monitoring displacement data. For verification, this method is applied to calculate the strain field of the Nuozhadu core wall rockfill dam. The results show that the proposed method can provide regulatory agencies with an effective tool for dam inspection during initial impoundment.
\end{abstract}

\section{Introduction}

The safety of core wall rockfill dams during initial impoundment has always been a critical issue considered by geotechnical structure engineers and regulatory agencies. In the case of the Teton Dam [1], the dam failed a few hours after excessive leakage was first observed. An incident occurred at Hyttejuvet Dam [2] in Norway when unexpected leakage occurred during the first filling of the reservoir. A similar leakage incident occurred just before the reservoir became full during the initial impoundment of Balderhead Dam in England [3]. This critical failure mode is difficult to detect in the early stages of impoundment and typically is not identified until it has progressed to a full piping leakage situation [4]. Therefore, it is particularly important in practice to develop a method with some predictive capability to assess potential problems in advance.

Foster el al. [5] conducted a statistical analysis of embankment dams failures and accidents. The compilation of dam incidents included detailed characteristics of the dams, including dam zoning, core soil type, filter, compaction, foundation cutoff, and foundation geology information. Foster el al. [6] proposed a method of estimating the relative likelihood of failure of embankment dams by piping based on an analysis of collected historic failures and accidents. However, the method is only suitable for preliminary assessments to identify which dams should be prioritized for more detailed studies. Thus, the method provides only conceptual assessment and is not substitute for sound engineering assessment. A number of numerical analyses have been conducted to evaluate the performance of dams during reservoir filling. Rashidi and Mohsen [7] conducted a twodimensional numerical analysis of Gavoshan Dam based on a finite difference method. This dam is a rockfill dam with a clay core located in Iran. The results of the numerical analysis exhibited good consistency with measured values. Djarwadi et al. [8] analyzed Hyttejuvet Dam in Norway using a finite element method. The ability of the clay core configuration of the rockfill dam to resist hydraulic fracturing was studied, and 30 variations of the clay core materials were analyzed. Because numerical models and material parameters involve considerable uncertainty, it is difficult to directly apply numerical results to practical projects. Numerous laboratory and field tests have been conducted to study the mechanisms of hydraulic fracturing $[9,10]$. The experimental results indicate that hydraulic fracturing is mainly attributed to high water pressure and potential cracks. During initial impoundment, the water level rapidly rises, the permeability 
coefficient of the core material is small, and a high water pressure directly acts on the upstream face of the core wall. Therefore, it is necessary to identify potential tensile strain zones and shear strain concentration zones in which cracks may form.

Prototype monitoring is an important part of safety evaluation for rockfill dams [11-15]. In general, pore pressures, earth pressures, seepage pressures, seepage discharge, and displacement are measured during construction and the initial impoundment. However, the spatial resolution of piezometers may not be refined enough to detect local defects [16]. In addition, variations in the pressures and seepage discharge lag behind the formation of seepage channels, which is a distinct warning sign of seepage failure. In this paper, based on prototype monitoring displacement, the authors focus on the reconstruction of the strain field of rockfill dams to identify the potential cracking zones and evaluate the performance of dams during initial impoundment.

To construct the strain field of a prototype rockfill dam, in mathematical theory, the strain can be computed from the numerical differentiation of monitoring displacement data. The accuracy of the strain field mainly depends on the quality of the monitoring displacement data. Unfortunately, considering the complexity of field monitoring conditions, monitoring displacement data are inevitably influenced by noise. Moreover, numerical differentiation is an unstable and uncertain operation, and derivations can considerably amplify the noises error contained in monitoring displacement data, which can lead to the severe distortion of the strain field [17]. Many researchers have explored effective displacement smoothing methods to suppress noise effects. These smoothing methods can be roughly classified into two categories: local and global smoothing methods. The performance of local smoothing methods [18-21] relies on properly sized calculation window. Selecting a proper window size is difficult because deformation issues are inhomogeneous. In addition, these methods require numerous markers for calibration, and such marker cannot be obtained by the monitoring system of a rockfill dam. In global smoothing methods, all noisy displacements are considered as a whole and fitted by piecewise interconnecting basis functions. Finite element-based (FE-based) smoothing methods, which are global smoothing methods, are effective noncontact methods of strain field measurement in experimental mechanics [22, 23]. This approach employs a finite element framework to establish a global description of the displacement field and determines the displacements at nodes. Because the monitoring gauges are limited and the approximation function is constructed based on a predefined mesh, the size of the mesh should be very coarse and cover the region of interest; thus, the accuracy of the solution is greatly affected by mesh distortion. Unlike the finite element method, the approximation function in the mesh-free method is constructed based on a series of nodes that are independent of a mesh. In particular, the radial basis function (RBF) method, which is a powerful mathematical approach [24], has proven useful for approximating scattered data. Therefore, a meshless smooth method based on the RBF method is proposed to process the prototype monitoring displacement data. After

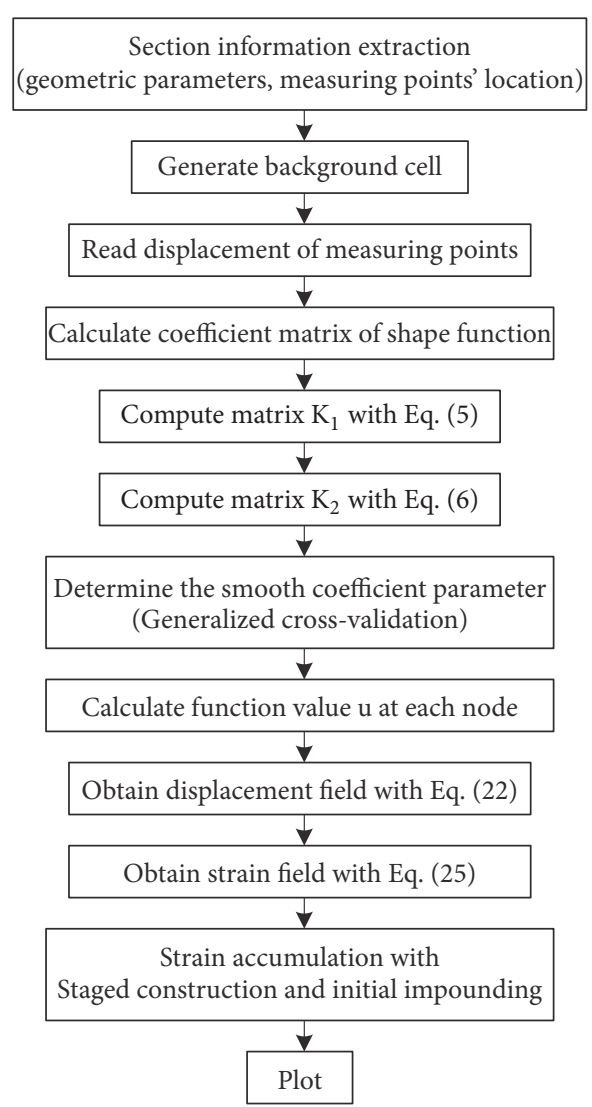

FIGURE 1: Flowchart of displacement and strain field analysis.

the smoothing of the displacements field, the strain field is obtained by differentiation.

In this paper, a meshless smoothing method that can identify potential tensile strain zones and shear strain concentration zones is presented to evaluate the performance of dams. First, the smoothing method for displacement and strain field analysis is illustrated in detail. Then, the Nuozhadu core wall rockfill dam is taken as an example to demonstrate the feasibility of the method. The strain field is calculated during initial impoundment, and several meaningful conclusions are drawn.

\section{The Meshless Smoothing Method for Displacement and Strain Analysis}

The flowchart of the meshless smoothing method for displacement and strain analysis is illustrated in Figure 1. This procedure includes four parts: a cluster of positive definite functions $[23,25]$, a shape function matrix $[26,27]$, a smoothing coefficient $[28,29]$, and strain accumulation with staged construction and impoundment. These parts will be briefly introduced in this section.

2.1. The Cluster of Positive Definite Functions. First, a cluster of positive definite functions $F(f, \lambda)[23,25]$ is introduced. The approximation function $f$ that minimizes the function 
$F(f, \lambda)$ is the smooth displacement field. The function is expressed as follows:

$$
\begin{aligned}
F(f, \lambda) & =\frac{1}{n} \sum_{j=1}^{n} h_{j}^{2}(f)+\lambda J(f) \\
h_{j}(f) & =\widetilde{f}\left(x_{j}, y_{j}\right)-f_{j}, \quad j=1,2, \ldots, n \\
J(f) & =\iint_{A}\left(f_{x x}^{2}+2 f_{x y}^{2}+f_{y y}^{2}\right) \mathrm{d} x \mathrm{~d} y
\end{aligned}
$$

where $\widetilde{f}\left(x_{j}, y_{j}\right)$ is the monitoring displacement; $f_{j}$ is the smoothed displacement at the monitoring point $\left(x_{j}, y_{j}\right)$; $h_{j}(f)$ is the "closeness" of the smoothed displacement field to the monitoring displacement; $J(f)$ defines the smoothness within the domain $A ; n$ is the number of monitoring points; and $\lambda$ is the smoothing coefficient. Additionally, $f_{x x}, f_{x y}, f_{y y}$ are second derivatives of $f$, where $f_{x x}=\partial^{2} f / \partial x^{2}, f_{x y}=$ $\partial^{2} f / \partial x \partial y$, and $f_{y y}=\partial^{2} f / \partial y^{2}$, respectively.

Since the analytical solution to this problem requires solving a biharmonic equation, a numerical solution was adopted to solve this function. Because the approximation function in the mesh-free method is constructed based on a series of nodes and is independent of a mesh, the radial point interpolation method was adopted. In the meshless method, the displacement $f$ at point $\left(x_{j}, y_{j}\right)$ can be expressed as $f_{j}=\phi_{k}\left(x_{j}, y_{j}\right) u_{k}, k=1,2, \ldots n$, where $\phi_{k}\left(x_{j}, y_{j}\right)$ is the shape function and $u_{k}$ is a nodal parameter. Namely, $f(\mathbf{x})=$ $\boldsymbol{\varphi}(\mathbf{x}) \mathbf{u}$, in which $\varphi$ is the matrix of the shape function and $\mathbf{u}$ is a column vector containing the nodal parameters. The derivatives of the approximation function $f$ can be expressed as follows:

$$
\begin{aligned}
\left(\frac{\partial^{2} f}{\partial x^{2}}\right)^{2} & =\left(\frac{\partial^{2} \boldsymbol{\varphi}}{\partial x^{2}} \mathbf{u}\right)^{\mathrm{T}}\left(\frac{\partial^{2} \boldsymbol{\varphi}}{\partial x^{2}} \mathbf{u}\right) \\
\left(\frac{\partial^{2} f}{\partial x \partial y}\right)^{2} & =\left(\frac{\partial^{2} \boldsymbol{\varphi}}{\partial x \partial y} \mathbf{u}\right)^{\mathrm{T}}\left(\frac{\partial^{2} \boldsymbol{\varphi}}{\partial x \partial y} \mathbf{u}\right) \\
\left(\frac{\partial^{2} f}{\partial y^{2}}\right)^{2} & =\left(\frac{\partial^{2} \boldsymbol{\varphi}}{\partial y^{2}} \mathbf{u}\right)^{\mathrm{T}}\left(\frac{\partial^{2} \boldsymbol{\varphi}}{\partial y^{2}} \mathbf{u}\right) \\
\frac{\partial f_{j}^{2}}{\partial u_{k}} & =2 \boldsymbol{\varphi}\left(x_{j}, y_{j}\right)^{\mathrm{T}} \boldsymbol{\varphi}\left(x_{j}, y_{j}\right) u_{k}
\end{aligned}
$$
that

The minimization of $F(f, \lambda)$ with respect to $\mathbf{u}$ requires

$$
\frac{\partial F(f, \lambda)}{\partial \mathbf{u}}=\mathbf{0}
$$

After substituting (2) into (3), the following equation can be obtained:

$$
\begin{aligned}
& \frac{1}{n} \sum_{j=1}^{n}\left[\boldsymbol{\varphi}\left(x_{j}, y_{j}\right)^{\mathrm{T}} \boldsymbol{\varphi}\left(x_{j}, y_{j}\right) \mathbf{u}-\boldsymbol{\varphi}\left(x_{j}, y_{j}\right)^{T} \tilde{f}\left(x_{j}, y_{j}\right)\right] \\
& \quad+\lambda \iint_{A}\left[\left(\frac{\partial^{2} \boldsymbol{\varphi}}{\partial x^{2}}\right)^{\mathrm{T}}\left(\frac{\partial^{2} \boldsymbol{\varphi}}{\partial x^{2}}\right)^{\mathrm{T}}\right.
\end{aligned}
$$

$$
\begin{aligned}
& +2\left(\frac{\partial^{2} \boldsymbol{\varphi}}{\partial x \partial y}\right)^{\mathrm{T}}\left(\frac{\partial^{2} \boldsymbol{\varphi}}{\partial x \partial y}\right)^{\mathrm{T}} \\
& \left.+\left(\frac{\partial^{2} \boldsymbol{\varphi}}{\partial y^{2}}\right)^{\mathrm{T}}\left(\frac{\partial^{2} \boldsymbol{\varphi}}{\partial y^{2}}\right)^{\mathrm{T}}\right] d A \mathbf{u}=\mathbf{0}
\end{aligned}
$$

Let

$$
\begin{aligned}
\mathbf{K}_{1} & =\frac{1}{n} \sum_{j=1}^{n} \boldsymbol{\varphi}\left(x_{j}, y_{j}\right)^{T} \boldsymbol{\varphi}\left(x_{j}, y_{j}\right) \\
\mathbf{K}_{2} & =\iint_{A}\left[\left(\frac{\partial^{2} \boldsymbol{\varphi}}{\partial x^{2}}\right)^{\mathrm{T}}\left(\frac{\partial^{2} \boldsymbol{\varphi}}{\partial x^{2}}\right)^{\mathrm{T}}\right. \\
& +2\left(\frac{\partial^{2} \boldsymbol{\varphi}}{\partial x \partial y}\right)^{\mathrm{T}}\left(\frac{\partial^{2} \boldsymbol{\varphi}}{\partial x \partial y}\right)^{\mathrm{T}} \\
& \left.+\left(\frac{\partial^{2} \boldsymbol{\varphi}}{\partial y^{2}}\right)^{\mathrm{T}}\left(\frac{\partial^{2} \boldsymbol{\varphi}}{\partial y^{2}}\right)^{\mathrm{T}}\right] d A \\
\mathbf{P} & =\frac{1}{n} \sum_{j=1}^{n} \boldsymbol{\varphi}\left(x_{j}, y_{j}\right)^{T} \tilde{f}\left(x_{j}, y_{j}\right)
\end{aligned}
$$

Equation (4) can now be rewritten as follows

$$
\left(\mathbf{K}_{1}+\lambda \mathbf{K}_{2}\right) \mathbf{u}-\mathbf{P}=\mathbf{0}
$$

A background cell structure is constructed for the numerical integration of matrix $\mathbf{K}_{2}$. Considering a typical section of rockfill dam, a triangular grid is discretized. According to relevant research $[30,31]$, as long as the number of Gaussian points is three to nine times the number of distributed nodes, high accuracy and convergence can be ensured. In this study, $\mathbf{K}_{2}$ was calculated with a 7-point Gauss numerical integration technique.

2.2. The Matrix of the Shape Function $\varphi$. The radial point interpolation method has the following two advantages. First, the moment matrix used in the construction of the shape functions is always invertible for irregular nodes. Second, the shape function is high-order derivable. Therefore, radial point interpolation was adopted as the approximation function. The procedure of constructing the matrix of the shape function is briefly introduced as follows.

Consider an approximation function $u(\mathbf{x})$ defined in the domain that has a set of arbitrarily distributed nodes $P_{i}\left(\mathbf{x}_{i}\right), i=1,2, \ldots n$. Let $u(\mathbf{x})$ pass through all nodes using the RBF $R_{i}(\mathbf{x})$ and polynomial basis function $p_{j}(\mathbf{x})$; then, the field function can be approximated as follows:

$$
u(\mathbf{x})=\sum_{i=1}^{n} R_{i}(\mathbf{x}) a_{i}+\sum_{j=1}^{m} p_{j}(\mathbf{x}) b_{j}=\mathbf{R}^{\mathrm{T}}(\mathbf{x}) \mathbf{a}+\mathbf{P}^{\mathrm{T}}(\mathbf{x}) \mathbf{b}
$$

where $R_{i}(\mathbf{x})$ is the RBF, $n$ is the number of nodes in the domain, $p_{j}(\mathbf{x})$ is the monomial basis function, and $m$ is the 
number of polynomial terms. $a_{i}$ and $b_{j}$ are coefficients. The vectors are defined as follows:

$$
\begin{aligned}
& \mathbf{a}^{\mathrm{T}}=\left[a_{1}, a_{2}, a_{3}, \ldots, a_{n}\right] \\
& \mathbf{b}^{\mathrm{T}}=\left[b_{1}, b_{2}, b_{3}, \ldots, b_{m}\right]
\end{aligned}
$$

The RBF is associated with the distance between the interpolation point and the node. This distance in Euclidean two-dimensional space is expressed as follows:

$$
r_{i}=\left[\left(x-x_{i}\right)^{2}+\left(y-y_{i}\right)^{2}\right]^{1 / 2}
$$

The polynomial basis has the following monomial terms:

$$
\mathbf{P}^{\mathrm{T}}(\mathbf{x})=[1, x, y]
$$

The coefficients $a_{i}$ and $b_{j}$ are determined by enforcing the interpolation pass through all $n$ scattered nodal points within the domain. The interpolation at the $k$ th point can be written as follows:

$$
u_{k}=\sum_{i=1}^{n} a_{i} R_{i}\left(x_{k}, y_{k}\right)+\sum_{j=1}^{m} b_{j} P_{j}\left(x_{k}, y_{k}\right)
$$

The polynomial term is an extra requirement that guarantees a unique approximation. In addition, the following constraint is typically imposed.

$$
\sum_{i=1}^{n} p_{j}\left(x_{i}, y_{i}\right) a_{i}=0, \quad j=1,2, \ldots, m
$$

Equation (15) can be expressed in matrix form as follows:

$$
\left[\begin{array}{cc}
\mathbf{R}_{0} & \mathbf{P}_{0} \\
\mathbf{P}_{0}^{\mathrm{T}} & \mathbf{0}
\end{array}\right]\left\{\begin{array}{l}
\mathbf{a} \\
\mathbf{b}
\end{array}\right\}=\left\{\begin{array}{l}
\mathbf{u} \\
\mathbf{0}
\end{array}\right\}
$$

or

$$
\mathbf{G}\left\{\begin{array}{l}
\mathbf{a} \\
\mathbf{b}
\end{array}\right\}=\left\{\begin{array}{l}
\mathbf{u} \\
\mathbf{0}
\end{array}\right\}
$$

where the vector of the function values is defined as

$$
\mathbf{u}=\left[u_{1}, u_{2}, u_{3}, \ldots, u_{n}\right]^{\mathrm{T}}
$$

The coefficient matrix $\mathbf{R}_{0}$ is

$$
R_{0}=\left[\begin{array}{cccc}
R_{1}\left(r_{1}\right) & R_{2}\left(r_{1}\right) & \cdots & R_{n}\left(r_{1}\right) \\
R_{1}\left(r_{2}\right) & R_{2}\left(r_{2}\right) & \cdots & R_{n}\left(r_{2}\right) \\
\vdots & \vdots & \ddots & \vdots \\
R_{1}\left(r_{n}\right) & R_{2}\left(r_{n}\right) & \cdots & R_{n}\left(r_{n}\right)
\end{array}\right]_{n \times n}
$$

in which $R_{i}(x, y)=r_{i}^{2} \log r_{i}$.

The coefficient matrix $\mathbf{P}_{0}$ is as follows:

$$
P_{0}=\left[\begin{array}{cccc}
1 & 1 & \cdots & 1 \\
x_{1} & x_{2} & \cdots & x_{n} \\
\vdots & \vdots & \ddots & \vdots \\
p_{m}\left(x_{1}\right) & p_{m}\left(x_{2}\right) & \cdots & p_{m}\left(x_{n}\right)
\end{array}\right]_{n \times m}
$$

The distance is directionless, and $R_{k}\left(x_{i}, y_{i}\right)=R_{i}\left(x_{k}, y_{k}\right)$, which means that matrix $\mathbf{R}_{0}$ is symmetric. A unique solution is obtained if the inverse of matrix $\mathbf{G}$ exists.

$$
\left\{\begin{array}{l}
\mathbf{a} \\
\mathbf{b}
\end{array}\right\}=\mathbf{G}^{-1}\left\{\begin{array}{l}
\mathbf{u} \\
\mathbf{0}
\end{array}\right\}
$$

The interpolation can finally be expressed as follows:

$$
u(\mathbf{x})=\left[\mathbf{R}^{\mathrm{T}}(\mathbf{x}) \mathbf{P}^{\mathrm{T}}(\mathbf{x})\right] \mathbf{G}^{-1}\left\{\begin{array}{l}
\mathbf{u} \\
\mathbf{0}
\end{array}\right\}=\boldsymbol{\varphi}(\mathbf{x}) \mathbf{u}
$$

where the matrix of the shape function $\varphi(\mathbf{x})$ is defined as

$$
\boldsymbol{\varphi}(\mathbf{x})=\left[\phi_{1}(\mathbf{x}), \phi_{2}(\mathbf{x}), \ldots, \phi_{i}(\mathbf{x}), \ldots \phi_{n}(\mathbf{x})\right]
$$

in which

$$
\phi_{k}(\mathbf{x})=\sum_{i=1}^{n} R_{i}(\mathbf{x}) \bar{G}_{i, k}+\sum_{j=1}^{m} P_{j}(\mathbf{x}) \bar{G}_{n+j, k}
$$

where $\bar{G}_{i, k}$ is the $(i, k)$ element of matrix $\mathbf{G}^{-1}$. The derivatives of the shape function are as follows:

$$
\begin{aligned}
& \frac{\partial \phi_{k}}{\partial x}=\sum_{i=1}^{n} \frac{\partial R_{i}}{\partial x} \bar{G}_{i, k}+\sum_{j=1}^{m} \frac{\partial P_{i}}{\partial x} \bar{G}_{n+j, k} \\
& \frac{\partial \phi_{k}}{\partial y}=\sum_{i=1}^{n} \frac{\partial R_{i}}{\partial y} \bar{G}_{i, k}+\sum_{j=1}^{m} \frac{\partial P_{i}}{\partial y} \bar{G}_{n+j, k}
\end{aligned}
$$

2.3. The Smoothing Coefficient $\lambda$. It is apparent that the smoothing parameter $\lambda$ controls the balance between the "closeness" and "smoothness." Generalized cross-validation (GCV) is a well-known and effective method of determining the optimal smoothing parameter $\lambda_{\text {opt }}[25,26]$. In short, GCV applies the "leave-one-out" principle, and $\lambda_{\text {opt }}$ minimizes the following error function:

$$
\operatorname{GCV}(\lambda)=\frac{n\|[\mathbf{I}-\mathbf{A}(\lambda)] \mathbf{y}\|^{2}}{\{\operatorname{tr}[\mathbf{I}-\mathbf{A}(\lambda)]\}^{2}}
$$

where

$$
\begin{aligned}
& \mathbf{A}(\lambda)=\mathbf{X}\left(\mathbf{X}^{\mathrm{T}} \mathbf{X}+\lambda \mathbf{K}_{2}\right)^{-1} \mathbf{X}^{\mathrm{T}} \\
& \mathbf{X}^{\mathrm{T}} \mathbf{X}=\mathbf{K}_{1} \\
& \mathbf{X}^{\mathrm{T}} \mathbf{y}=\mathbf{P}
\end{aligned}
$$

A complete description of an algorithm based on the interval analysis is given [29]. This algorithm obtains the globally optimal value $\lambda$ for $2 \mathrm{D}$ problems. $\mathbf{u}$ can be determined by substituting $\lambda_{\text {opt }}$ into (8). Then, the displacement and strain fields can easily be obtained using (22) and (25).

2.4. Strain Accumulation with Staged Construction and Impoundment. During staged construction, monitoring gauges are installed only if construction reaches a certain 


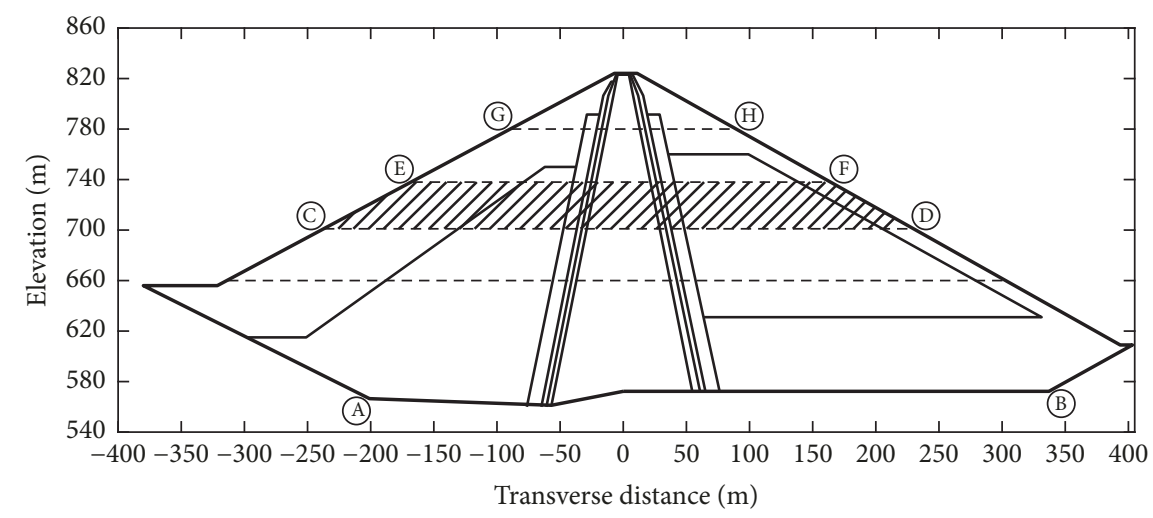

FIGURE 2: The scheme of strain accumulation.

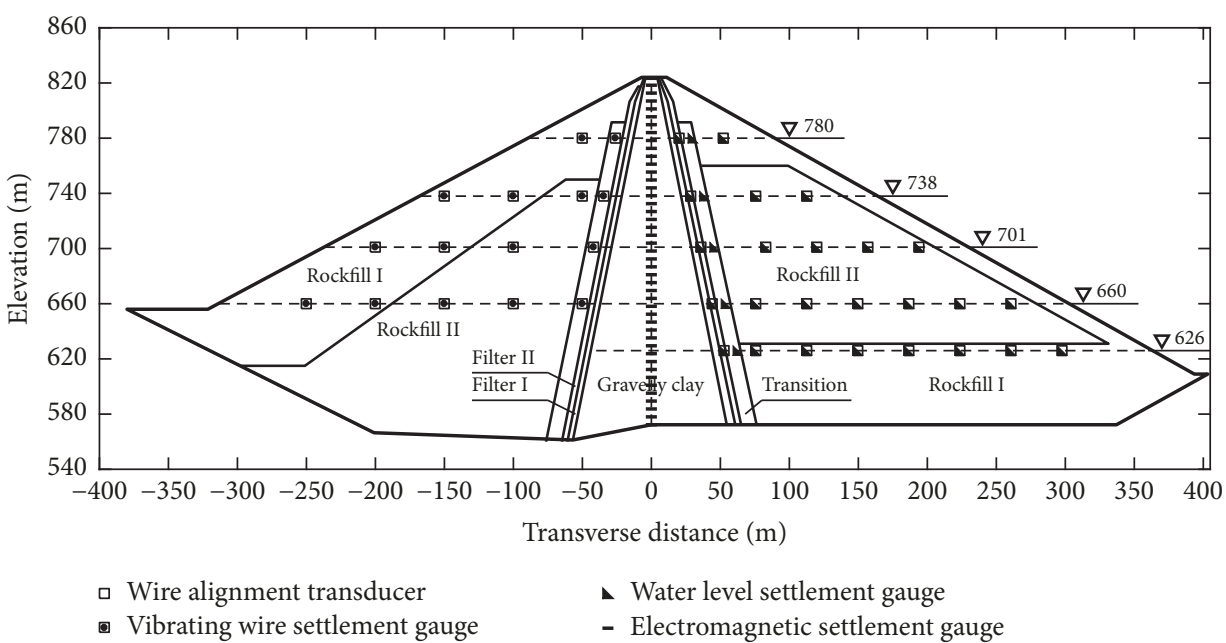

FIgURe 3: The typical section of the Nuozhadu core wall rockfill dam (section $0+309$ ).

elevation. Namely, the starting times of measuring points are different, so these raw monitoring displacement data cannot be directly employed. Because the deformation process of rockfill dams is nonlinear, a strain accumulation strategy was adopted, as illustrated in Figure 2. During the staged construction process, the load layer (CDEF) causes incremental deformation in the completed profile (ABEF), which is below the construction elevation. The load layer (CDEF) has no effect on the zone above the construction elevation (EFGH). Therefore, the strain increment of the completed profile (ABEF) can be derived from the incremental deformation caused by the load layer. Based on this method, the strain accumulation process can be effectively simulated for staged construction and initial impoundment.

\section{The Nuozhadu Core Wall Rockfill Dam}

The Nuozhadu water control project is located on the main stream of the lower Lancang River near Pu'er City in Yunnan Province, China. The project provides irrigation, water supply, power generation, flood control, environmental protection, tourism, and other functions. The total installed capacity of the hydropower station is $5,850 \mathrm{MW}$, and the designed annual average power output is $239 \times 108 \mathrm{~kW} \cdot \mathrm{h}$.

The maximum cross section of the dam with material zoning is shown in Figure 3. The dam has a maximum height of $261.5 \mathrm{~m}$ with an upstream slope of 1:1.9 and a downstream slope of 1:1.8. There are six types of dam materials: rockfill I, rockfill II, filter I, filter II, transition, and gravelly clay. According to the large-scale consolidation test, the compression modulus of core material is $32.9 \sim 73.2 \mathrm{MPa}$, and the compression modulus of rockfill materials is $112.0 \sim 190.5 \mathrm{MPa}$ in saturation condition and 208.2 368.1MPa in unsaturation condition. The E-B model parameters of materials of Nuozhadu core wall rockfill dam are provided in Table 1.

The construction and initial impoundment process of the Nuozhadu core wall rockfill dam are shown in Figure 4 . The construction started in January 2008 and ended at the end of December 2012. The construction was organized based on full section balanced filling, and the construction of the core wall was shut down in the flood season each year. The upstream water level was almost constant at EL. $605.0 \mathrm{~m}$ before December 2011; then, the water level gradually rose during the initial impoundment process. At the end of 2012, the construction reached EL. $808.0 \mathrm{~m}$, and the upstream 
TABLE 1: The E-B model parameters of the Nuozhadu dam materials.

\begin{tabular}{lccccccc}
\hline Dam materials & $K$ & $n$ & $R_{f}$ & $K_{b}$ & $m$ & $\phi\left(^{\circ}\right)$ & $\Delta \phi\left(^{\circ}\right)$ \\
\hline Rockfill I & 1425 & 0.26 & 0.73 & 540 & 0.16 & 54.2 & 10.1 \\
Rockfill II & 1530 & 0.175 & 0.76 & 376 & 0.1 & 50.6 \\
Gravelly clay & 421 & 0.56 & 0.78 & 299 & 0.25 & 43.52 \\
Transition & 1100 & 0.28 & 0.69 & 530 & 0.12 & 50.54 & 11.38 \\
Filter I & 1240 & 0.176 & 0.78 & 254 & 0.1 & 6.73 \\
Filter II & 1450 & 0.176 & 0.78 & 350 & 0.15 & 54.9 \\
\hline
\end{tabular}

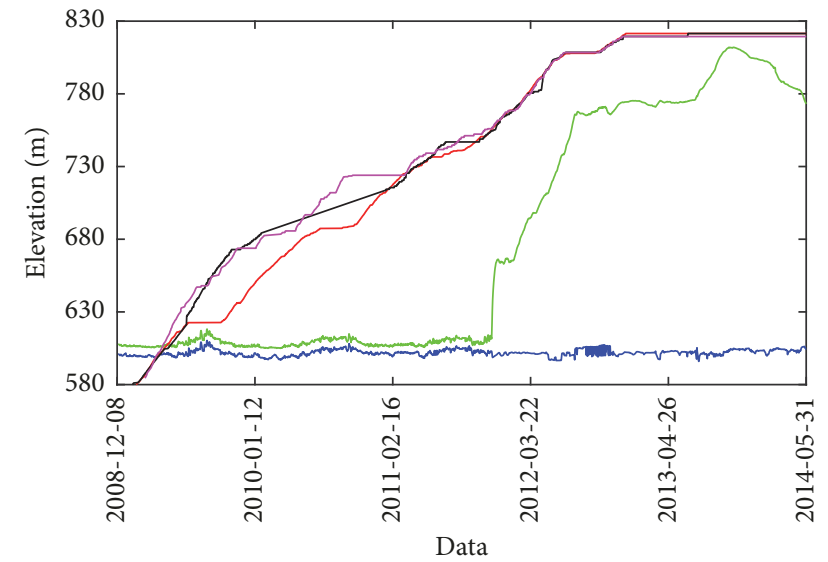

_ upstream water level

_ downstream water level

- construction elevation of core

_ construction elevation of upstream rockfill

_ construction elevation of downstream rockfill

Figure 4: The construction and impounding process of the Nuozhadu core wall rockfill dam.

water level reached EL. $774.0 \mathrm{~m}$. At this point, the initial impoundment was completed.

\section{The Displacement Monitoring System}

A detailed displacement monitoring system was established to monitor the deformation of the Nuozhadu core wall rockfill dam. The settlement and horizontal displacement inside the dam were measured with vibrating wire settlement gauges, water level settlement gauges, wire alignment transducers, and electromagnetic settlement gauges distributed in three typical cross sections: $0+169,0+309$, and $0+482$. The layout of the displacement monitoring system in section $0+309$ is shown in Figure 5. To date, large quantities of field monitoring data have been collected as shown in Figures 6-10.

\section{Strain Analysis of the Nuozhadu Core Wall Rockfill Dam}

The monitoring data in section $0+309$ were processed with the meshless smoothing method. Then, the smoothed displacement and strain fields were obtained. Some meaningful conclusions were drawn by analyzing the calculated stain field.

5.1. The Smoothed Displacement Field of Section 0+309 of the Dam. The settlement contour before reservoir filling is illustrated in Figure 11. The maximum settlement in the core wall occurred at EL. $660.0 \mathrm{~m}$. The settlement of the upstream and downstream rockfill shells reached a maximum at the same elevation. The maximum settlement of the core wall was slightly larger than that of the rockfill shells. As shown, the settlement contour is generally symmetric with respect to the dam axis, which is mainly due to the low upstream water level and full-face balance construction.

Figure 12 shows the settlement contour after initial impoundment. The settlement of the core wall reached a maximum of $3.0 \mathrm{~m}$. The maximum settlement of the upstream and downstream rockfill shells was $2.5 \mathrm{~m}$ and $2.0 \mathrm{~m}$, respectively. The elevations of maximum settlement in the core wall and downstream rockfill shell were higher than that in the upstream shell. However, the settlement of the upstream shell was larger than that of the downstream shell. This phenomenon may be attributed to the combination of floatage and wetting effects.

As shown in Figure 13, the horizontal displacement contour was generally symmetric with respect to the dam axis before reservoir filling. The maximum horizontal displacement occurred at the upstream and downstream slope surfaces at $1 / 2$ the filling height. Meanwhile, relatively horizontal displacement was observed near the interface between the shells and core wall. The core wall material was softer than the rockfill, and the rolling compaction of the core wall led to lateral extrusion, which was the main reason for this considerable horizontal displacement.

The horizontal displacement contour after initial impoundment is given in Figure 14. In general, the horizontal displacement moved downstream. The maximum horizontal displacement in the core wall reached $1.4 \mathrm{~m}$ at EL. $700.0 \mathrm{~m}$. During the first relatively rapid reservoir filling stage, steady seepage did not occur in the dam and the water pressure directly acted on the upstream surface of the core wall because the hydraulic conductivity of the core material was small. Therefore, the horizontal displacement in the core wall and downstream shell at EL. 660 740.0 $\mathrm{m}$ was larger than that in the upstream shell.

5.2. The Smoothed Strain Field of Section 0+309 of the Dam. The volumetric strain of section $0+309$ is given in Figure 15 . The volumetric strain in the upstream and downstream shells 


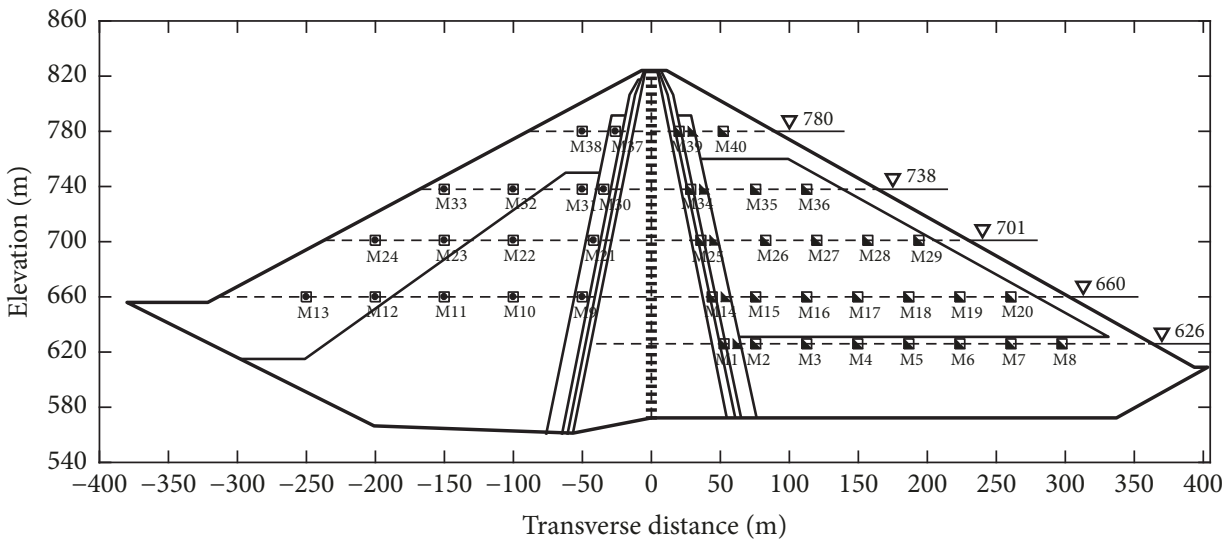

Figure 5: The layout of the displacement monitoring system in section $0+309$.

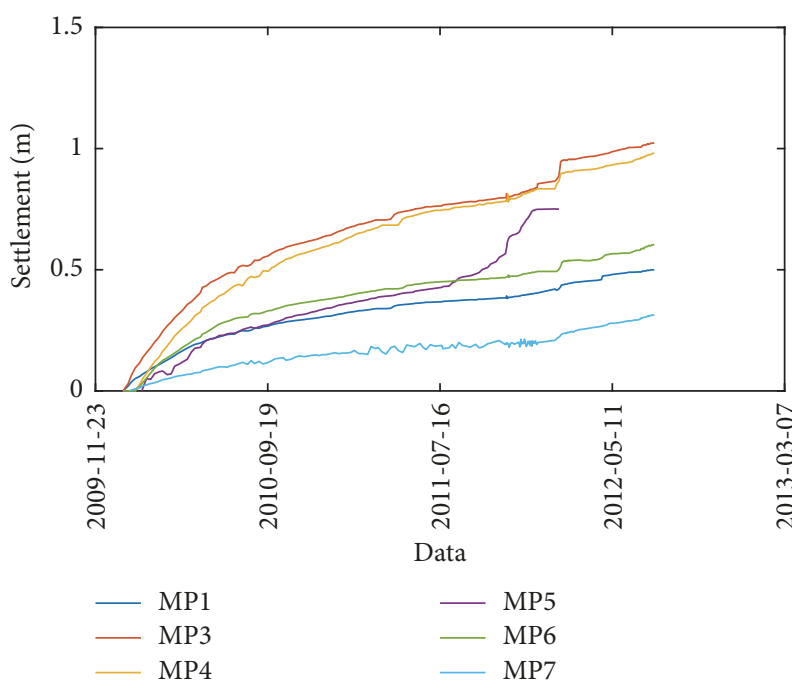

FIGURE 6: The settlement process of monitoring gauges at EL. $626 \mathrm{~m}$.
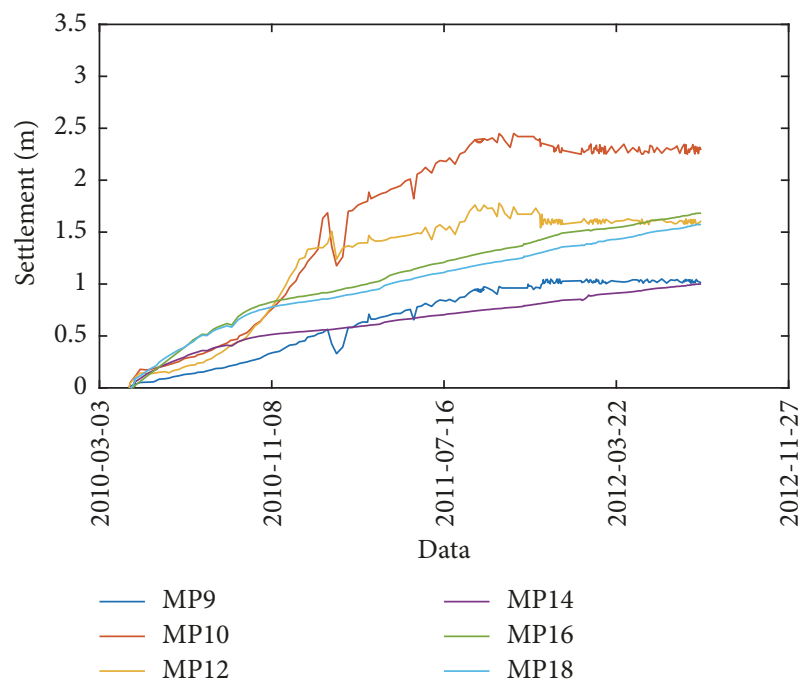

FIGURE 7: The settlement process of monitoring gauges at EL. $660 \mathrm{~m}$.

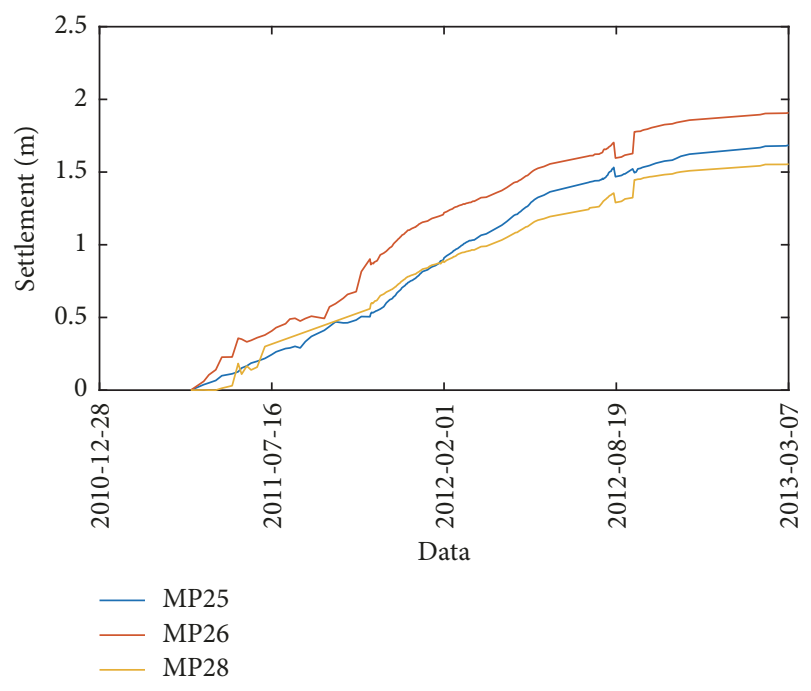

FIGURE 8: The settlement process of monitoring gauges at EL. $701 \mathrm{~m}$.

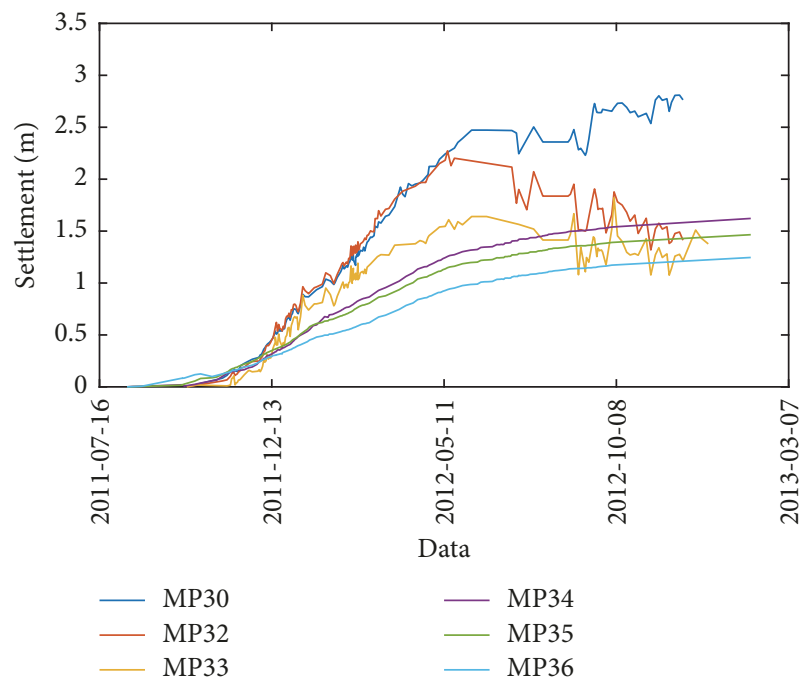

FIGURE 9: The settlement process of monitoring gauges at EL. $738 \mathrm{~m}$. 


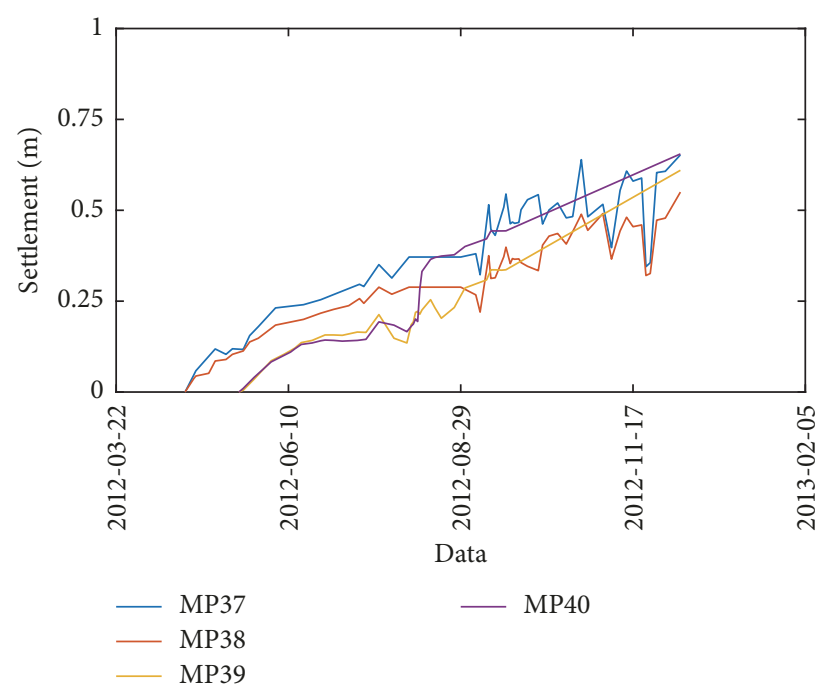

FIGURE 10: The settlement process of monitoring gauges at EL. $780 \mathrm{~m}$.

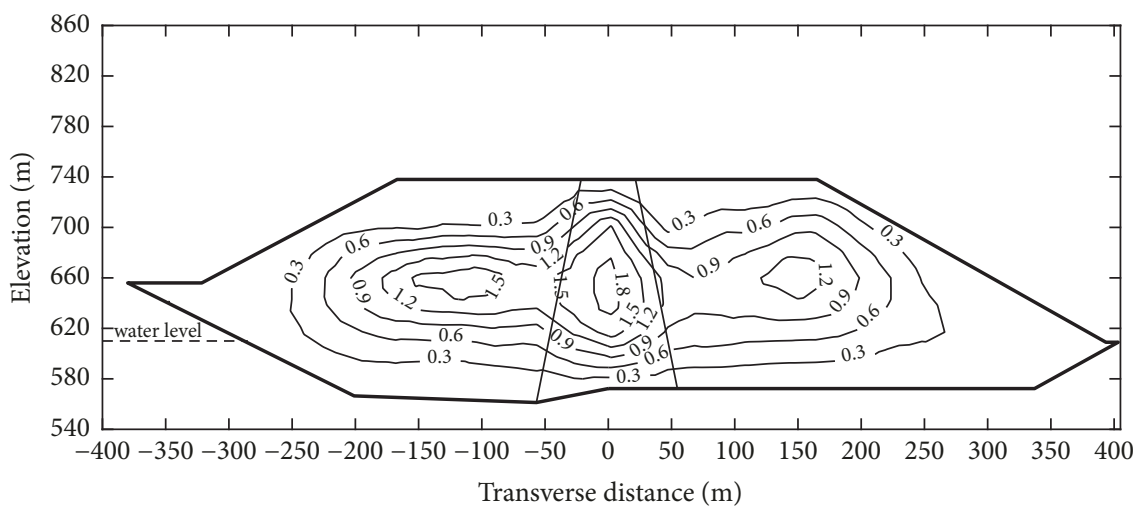

FIGURE 11: The settlement contour before initial impoundment in section 0+309 (unit: m).

reached maximum at EL. $660.0 \mathrm{~m}$ and EL. $700.0 \mathrm{~m}$, respectively. In addition, the maximum volumetric compression strain of the upstream rockfill zone was larger than that of the downstream shell. The upstream rockfill materials softened after immersion, which resulted in considerable stress variations. The extensive rearrangement of particles caused considerable plastic deformation. In the core wall, the volumetric strain exhibited a compression trend and reached a maximum of $2.5 \%$ at EL. $680.0 \sim 700.0 \mathrm{~m}$. In general, there was no volumetric expansion in the core wall, and the risk of concentrated leakage was negligible.

As shown in Figure 15, the calculated volumetric strain was extremely small, even reaching zero, at the upstream slope. This result maybe can be due to the unloading of floatage. For rockfill materials, when the volumetric strain approaches zero, the skeleton of rockfill loosens, and the strength decreases considerably and even disintegrates. The reverse seepage caused by reservoir drainage could lead to a shallow slide on the upstream slope. Therefore, the discharge of water from the reservoir should be carefully controlled.
The monitored pore water pressures right after initial impoundment are plotted in Figure 16. The pore water pressures were monitored by vibrating wire seepage pressure cells. $14 \# \sim 16 \#, 24 \sim 26 \#$, and 34\# were broken, but others worked as expected. After reservoir filling, the upstream water level reached EL. $774.0 \mathrm{~m}$. The monitored excess pore water pressure was $0.01 \mathrm{MPa}$, which was caused by roller compaction. The hydrostatic pressures were $0.36 \mathrm{MPa}, 0.73 \mathrm{MPa}, 1.14 \mathrm{Mpa}$, and $1.48 \mathrm{MPa}$ at the corresponding monitoring elevations. The excess pore water pressures were $0.05 \mathrm{MPa}$ and $0.11 \mathrm{MPa}$ at EL. $626.0 \mathrm{~m}$ and $701.0 \mathrm{~m}$, respectively. The readings of the 27\# pressure cell may be inaccurate. The excess pore water pressure reached a maximum of $0.27 \mathrm{MPa}$ at EL. $738.0 \mathrm{~m}$. During filling and initial impoundment process, the total stress acting on the core material increased, and then the soil skeleton was compressed and the void volume decreases. Since the permeability coefficient of core clayey material is quite small, the pore water cannot dissipate quickly, the excess pore pressure increased. In Figure 15, the compression strain exceeded $2.0 \%$ at EL. $680 \sim 740.0 \mathrm{~m}$, which was consistent with the locations of excess pore water pressures. Therefore, it can 


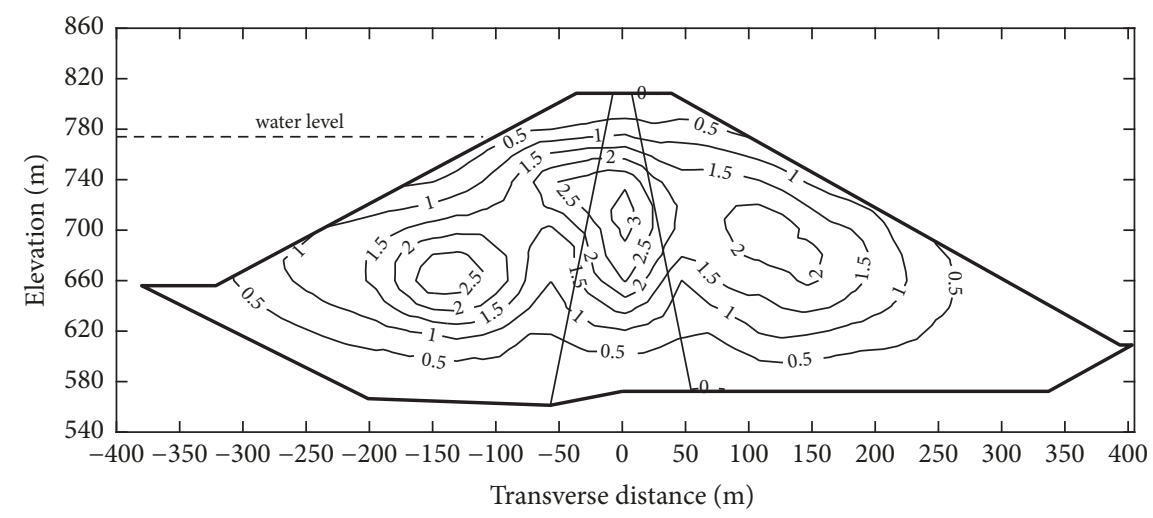

FIGURE 12: The settlement contour after impoundment in section 0+309 (unit: m).

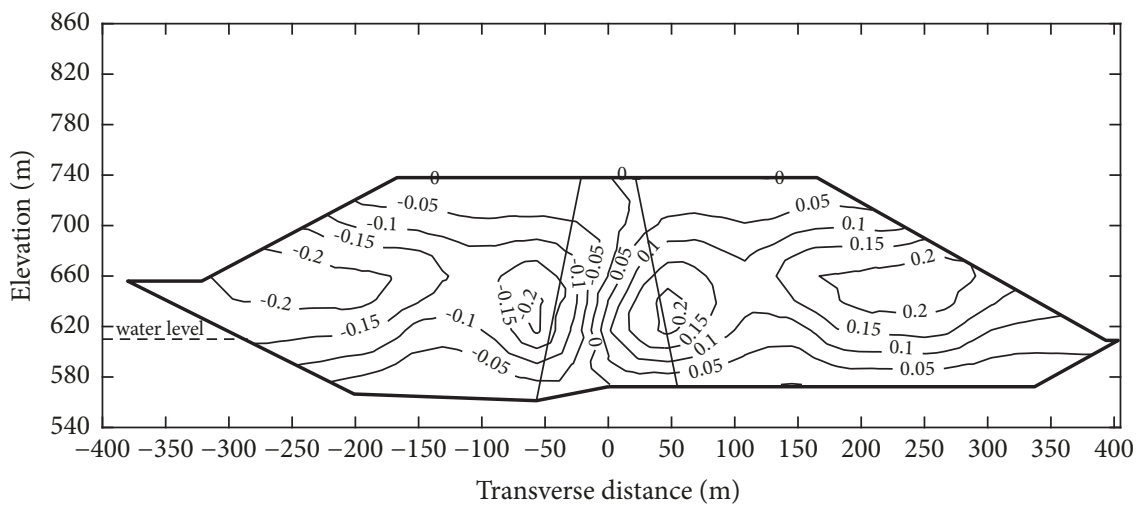

FIGURE 13: The horizontal displacement contour before initial impoundment in section 0+309 (unit: m).

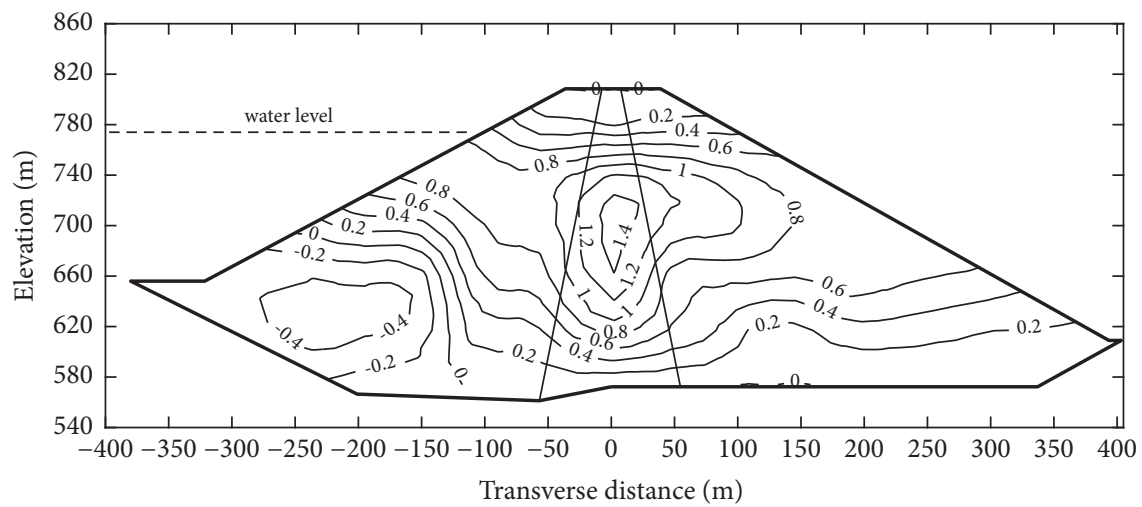

FIGURE 14: The horizontal displacement contour after impoundment in section 0+309 (unit: $\mathrm{m}$ ).

be concluded that the compression strain is a key factor that influences the excess pore water pressure in the core wall. The excess pore water pressure can reduce the effective stress and increase the risk of hydraulic fracturing, so the accumulation of excess pore water pressure in the core wall should be appropriately considered.

Figure 17 shows the shear strain field of section $0+309$. The calculated shear strain of the upstream and downstream slopes reached a maximum of $1 \%$. Because this shear strain is small, this slide did not endanger the safety of the dam slopes. The shear strain in the core wall reached the maximum of $2.0 \%$ and $1.0 \%$ on the upstream and downstream surfaces, respectively. In addition, the maximum occurred at EL. $700.0 \mathrm{~m}$, which was consistent with the position of maximum differential settlement between the core wall and rockfill shells in Figure 12. Because the core material is more compressible than the rockfill shells, the core wall will tend to settle more than the rockfill shells and can "hang up" on the rockfill shoulders, thereby lowering the stresses in the core wall. This "arching effect" often causes differential settlement cracking. Therefore, some gravel should be mixed into clay to increase the modulus of the core material and 


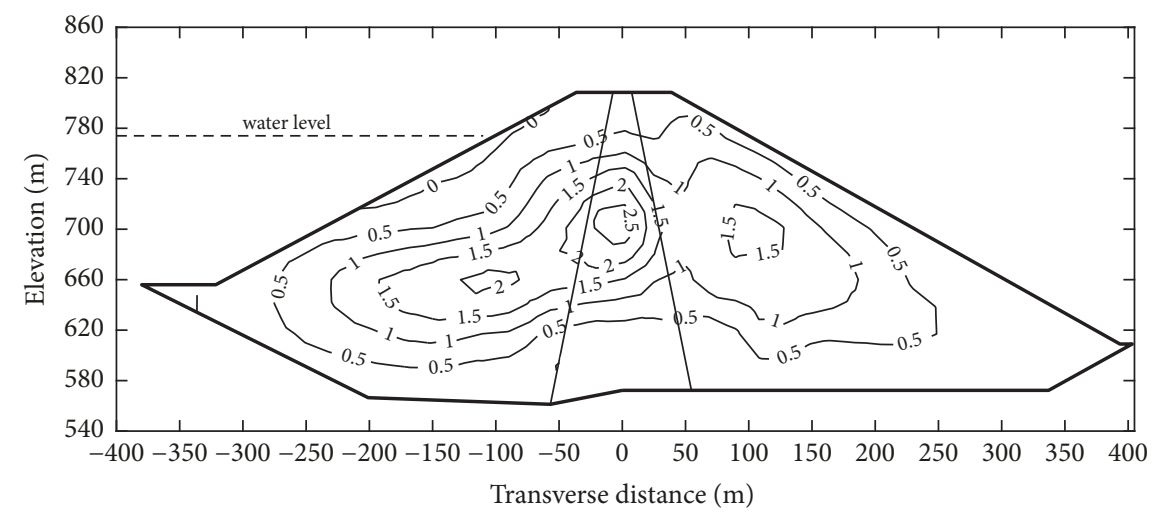

FIGURE 15: The volumetric strain after impoundment in section 0+309 (unit: \%, volume shrink is positive).

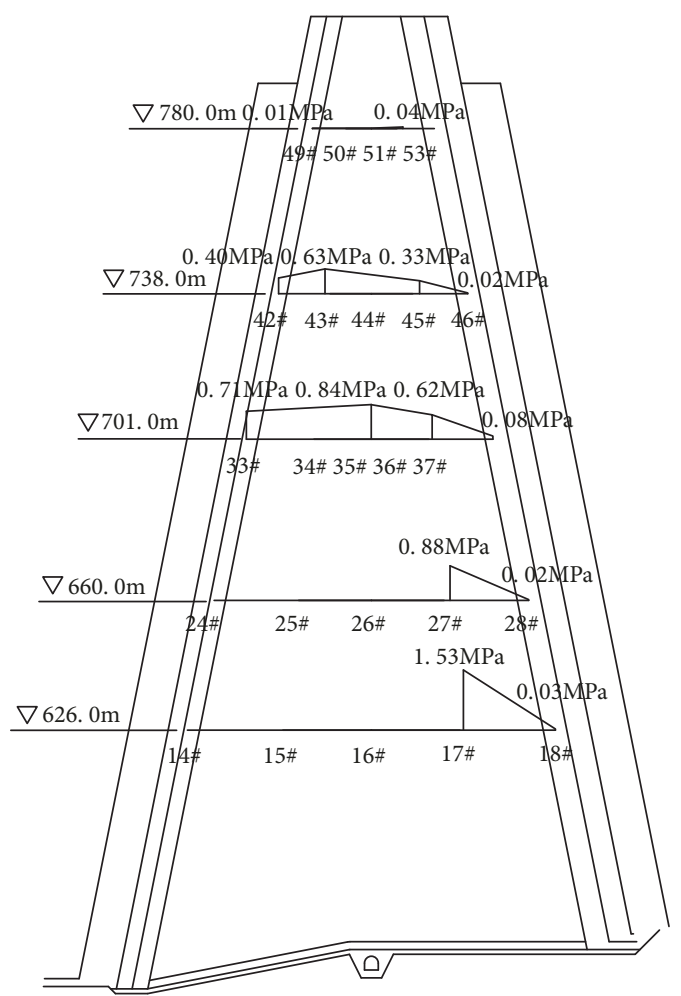

FIGURE 16: The monitoring pore water pressure after impoundment in section $0+309$.

reduce the differential deformation. In addition, fine rockfill materials should be used as transition layer to sustain the concentrated shear strain. Additionally, well-graded filters containing sufficient quantities of noncohesive fines should be adopted to seal the potential shear cracks in the core wall to improve the stability against seepage flow.

Compared with transverse displacement and settlement, the displacement along the dam axis was small. Based on the plane strain hypothesis, the principal strains can be calculated as follows: $\varepsilon_{1}, \varepsilon_{3}=(1 / 2)\left(\varepsilon_{x}+\varepsilon_{y} \pm \sqrt{\left(\varepsilon_{x}-\varepsilon_{y}\right)^{2}+\gamma_{x y}^{2}}\right)$. During the construction and reservoir filling stages, the direction of the major principal stress was vertical, and the direction of the minor principal stress was approximately horizontal. Therefore, the calculated minor principal stress $\varepsilon_{3}$ was in the transverse direction.

The calculated minor principal strain $\varepsilon_{3}$ contour is illustrated in Figure 18. As shown, the minor principal strain below EL. $720.0 \mathrm{~m}$ was generally symmetric with respect to the dam axis. The maximum $\varepsilon_{3}$ of $0.3 \%$ appeared near the downstream surface of the core wall at EL. $700.0 \mathrm{~m}$. After the initial impoundment, the water pressure acted on the core wall and caused horizontal displacement in the downstream direction (in Figure 14), which increased the minor principal strain on the downstream surface of the core wall.

In Figure 18, the minor principal strain $\varepsilon_{3}$ on the upstream shell and surface of the core wall dramatically decreased above EL. $700.0 \mathrm{~m}$. If the minor principal strain, which is nearly perpendicular to the core wall, decreases to zero, potential longitudinal cracks may occur. Therefore, periodical dam inspection should occur with a focus on the core wall and upstream shell near the dam crest.

\section{Conclusion}

It is important to evaluate the performance of rockfill dams during initial impoundment. The strain field of a prototype dam is an effective tool for identifying potential tensile strain zones and shear strain concentration zones in which cracks may form. A meshless smoothing method was proposed to process the prototype monitoring displacement data and construct the strain field of dams. This method provides an optimal balance between the data fitting capability and error sensitivity. Therefore, smooth displacement and strain fields of rockfill dams can be calculated with this method. The displacement and strain fields of the Nuozhadu core wall rockfill dam were analyzed with prototype monitoring data during initial impoundment, and the following conclusions were drawn:

(1) The volumetric strain of the core wall exhibited a compression trend. In general, there was no tensile strain in the core wall, so the risk of concentrated leakage was negligible. This indicates that the zoning design was adequate and the construction level was fairly high. 


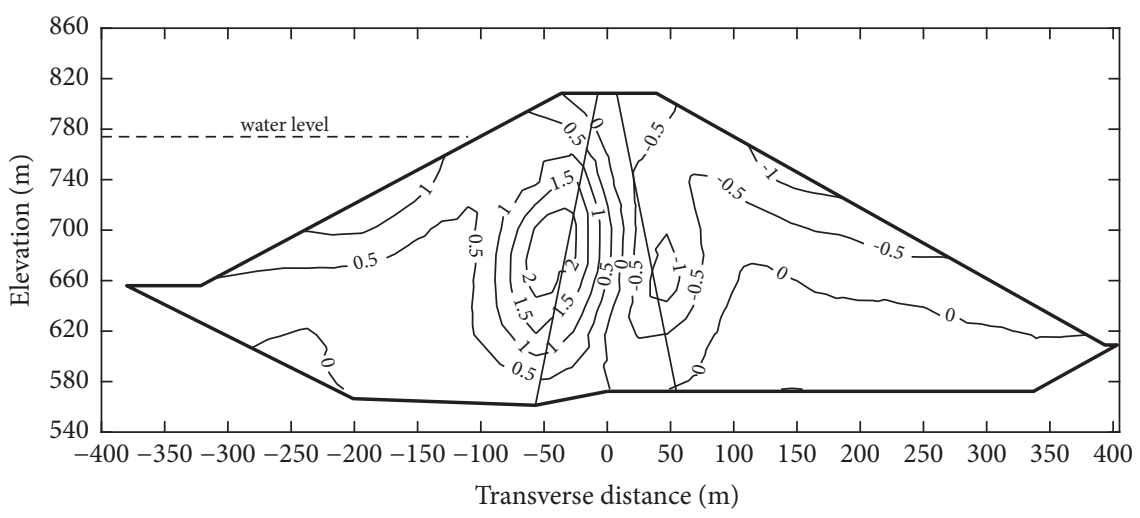

FIGURE 17: The shear strain after impoundment in section 0+309 (unit: \%).

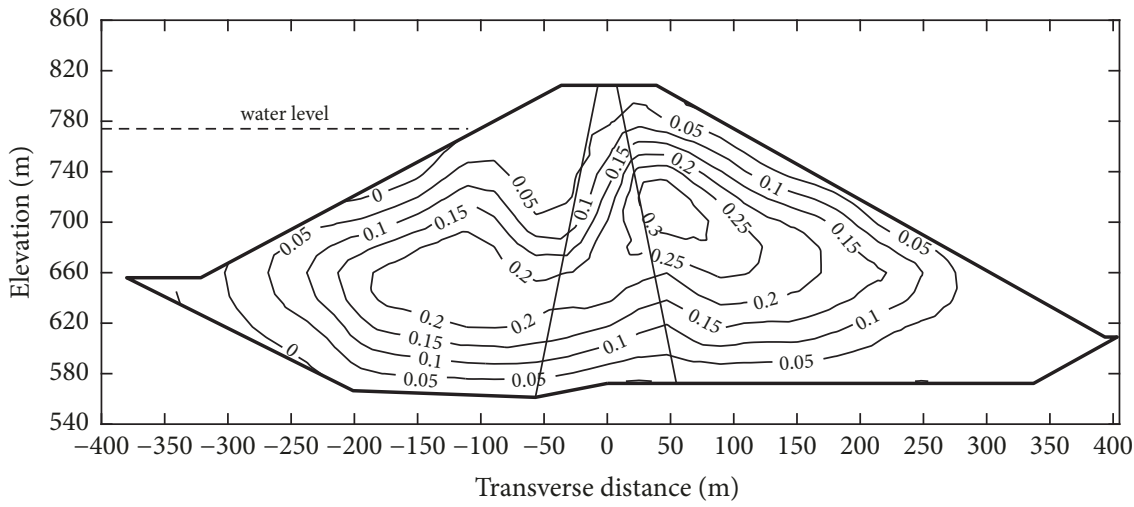

FIGURE 18: The third principal strain after impoundment in section 0+309 (unit: \%).

(2) A shear strain concentration zone appeared near the upstream and downstream surfaces in the middle of the core wall. This was due to differential settlement between the rockfill shells and the core wall of the dam. Compared with the upstream and downstream shells, the core materials are more compressible. Therefore, reinforcement measures, such as mixing with gravel, enhanced compaction energy, that improve the modulus of the core wall should be adopted. In addition, fine rockfill materials should be used as transition layer to sustain the concentrated shear strain. As remedial engineering measure, wellgraded filters containing sufficient quantities of noncohesive fines should be adopted to seal the potential shear cracks in the core wall.

(3) A considerable decrease in the minor principle strain occurred on the upstream shell and surface of the core wall above EL. $700.0 \mathrm{~m}$. If the minor principal strain, which is nearly perpendicular to the core wall, decreases to zero, potential longitudinal cracks may occur. Therefore, periodical dam inspections should focus on the core wall and upstream shell near the dam crest.

These results show that the proposed meshless smoothing method is effective for evaluating the performance of prototype rockfill dams during initial impoundment and can be conveniently used to assist in field inspections of dams.

\section{Data Availability}

The data used to support the findings of this study are available from the corresponding author upon request.

\section{Conflicts of Interest}

The authors declare that they have no financial and personal relationships with other people or organizations that can inappropriately influence their work. There is no professional or other personal interest of any nature or kind in any product, service, and/or company that could be construed as influencing the position presented in or the review of this manuscript.

\section{Acknowledgments}

This research was supported by the National Natural Science Foundation of China (no. 51379029) and the National Major Scientific Research Program in 13th Five-Year Plan (2016YFB0201001). 


\section{References}

[1] H. B. Seed, "The Teton dam a retrospective review," Soil Mechanics \& Foundation Engineering, vol. 30, pp. 15-16, 1982.

[2] D. M. Wood, B. Kjoernsli, and K. Hoeg, Thoughts Concerning the Unusual Behaviour of Hyttejuvet Dam, Norges Geotekniske Institutt, Norway, 1977.

[3] P. R. Vaughan and D. J. Kluth, Cracking and erosion of the rolled clay core of Balderhead dam and the remedial works adopted for its repair, Thomas Telford Publishing, 2009.

[4] R. Flores-Berrones, M. Ramírez-Reynaga, and E. J. Macari, "Internal erosion and rehabilitation of an earth-rock dam," Journal of Geotechnical and Geoenvironmental Engineering, vol. 137, no. 2, pp. 150-160, 2010.

[5] M. Foster, R. Fell, and M. Spannagle, "The statistics of embankment dam failures and accidents," Canadian Geotechnical Journal, vol. 37, no. 5, pp. 1000-1024, 2000.

[6] M. Foster, R. Fell, and M. Spannagle, "A method for assessing the relative likelihood of failure of embankmen," Canadian Geotechnical Journal, vol. 37, no. 2, pp. 495-496, 2002.

[7] M. Rashidi, M. Heidar, and G. Azizyan, "Numerical Analysis and Monitoring of an Embankment Dam During Construction and First Impounding (Case Study: Siah Sang Dam)," Scientia Iranica, 2017.

[8] D. Djarwadi, K. B. Suryolelono, and B. Suhendro, "Effect of Clay Core Configuration of the Rock Fill Dams Against Hydraulic Fracturing," Procedia Engineering, 2017.

[9] K. Y. Lo and K. Kaniaru, "Hydraulic fracture in earth and rockfill dams," Canadian Geotechnical Journal, vol. 27, no. 4, pp. 496506, 1990.

[10] J. Q. Deng, C. Lin, Q. Yang, Y. R. Liu, Z. F. Tao, and H. F. Duan, "Investigation of directional hydraulic fracturing based on true tri-axial experiment and finite element modeling," Computers \& Geosciences, vol. 75, pp. 28-47, 2016.

[11] S. Siddiqua, J. A. Blatz, and N. C. Privat, "Evaluating the behaviour of instrumented prototype rockfill dams," Canadian Geotechnical Journal, vol. 50, no. 3, pp. 298-310, 2013.

[12] R. V. Rinehart, M. L. Parekh, and J. B. Rittgers, "Preliminary implementation of geophysical techniques to monitor embankment dam filter cracking at the laboratory scale," in Proceedings of the 6th Annual International Conference on Software Engineering (ICSE), Paris, France, 2012.

[13] C. R. Song and T. Y. Yosef, "Seepage Monitoring of an Embankment Dam Based on Hydro-Thermal Coupled Analysis," Journal of Engineering Materials and Technology, vol. 139, no. 2, 2017.

[14] L. Wen, J. Chai, Z. Xu, Y. Qin, and Y. Li, "Monitoring and numerical analysis of behaviour of Miaojiaba concrete-face rockfill dam built on river gravel foundation in China," Computers \& Geosciences, vol. 85, pp. 230-248, 2017.

[15] M. Rashidi and S. M. Haeri, "Evaluation of behaviors of earth and rockfill dams during construction and initial impounding using instrumentation data and numerical modeling," Journal of Rock Mechanics and Geotechnical Engineering, vol. 9, no. 4, pp. 709-725, 2017.

[16] S. Johansson, Seepage Monitoring in Embankment Dams [Ph.D. thesis], Royal Institute of Technology, Stockholm, Sweden, 1997.

[17] M. A. Sutton, J. L. Turner, H. A. Bruck, and T. A. Chae, "Fullfield representation of discretely sampled surface deformation for displacement and strain analysis," Experimental Mechanics, vol. 31, no. 2, pp. 168-177, 1991.
[18] B. Pan, H. Xie, Z. Guo, and T. Hua, "Full-field strain measurement using a two-dimensional Savitzky-Golay digital differentiator in digital image correlation," Optical Engineering, vol. 46, no. 3, pp. 583-601, 2007.

[19] B. Pan, A. Asundi, H. Xie, and J. Gao, "Digital image correlation using iterative least squares and pointwise least squares for displacement field and strain field measurements," Optics and Lasers in Engineering, vol. 47, no. 7-8, pp. 865-874, 2009.

[20] S. Avril, P. Feissel, F. Pierron, and P. Villon, "Comparison of two approaches for differentiating full-field data in solid mechanics," Measurement Science and Technology, vol. 21, no. 1, 2009.

[21] B. Pan, B. Wang, and G. Lubineau, "Comparison of subset-based local and FE-based global digital image correlation: Theoretical error analysis and validation," Optics and Lasers in Engineering, vol. 82, pp. 148-158, 2016.

[22] L. B. Meng, G. C. Jin, and X. F. Yao, "Application of iteration and finite element smoothing technique for displacement and strain measurement of digital speckle correlation," Optics and Lasers in Engineering, vol. 45, no. 1, pp. 57-63, 2007.

[23] D. J. Segalman, D. B. Woyak, and R. E. Rowlands, "Smooth spline-like finite-element differentiation of full-field experimental data over arbitrary geometry," Experimental Mechanics, vol. 19, no. 12, pp. 429-437, 1979.

[24] M. D. Buhmann, Radial Basis Functions: Theory and Implementations, vol. 12 of Cambridge Monographs on Applied and Computational Mathematics, Cambridge University Press, Cambridge, UK, 2003.

[25] B. Pan, J. Yuan, and Y. Xia, "Strain field denoising for digital image correlation using a regularized cost-function," Optics and Lasers in Engineering, vol. 65, no. 0, pp. 9-17, 2014.

[26] G. R. Liu and Y. T. Gu, "A point interpolation method for two-dimensional solids," International Journal for Numerical Methods in Engineering, vol. 50, no. 4, pp. 937-951, 2001.

[27] G. R. Liu, Y. Li, K. Y. Dai, M. T. Luan, and W. Xue, "A linearly conforming radial point interpolation method for solid mechanics problems," International Journal of Computational Methods, vol. 3, no. 4, pp. 401-428, 2006.

[28] G. H. Golub, M. Heath, and G. Wahba, "Generalized crossvalidation as a method for choosing a good ridge parameter," Technometrics, vol. 21, no. 2, pp. 215-223, 1979.

[29] J. T. Kent and M. Mohammadzadeh, "Global optimization of the generalized cross-validation criterion," Statistics and Computing, vol. 10, no. 3, pp. 231-236, 2000.

[30] J. Dolbow and T. Belytschko, "Numerical integration of the Galerkin weak form in meshfree methods," Computational Mechanics, vol. 23, no. 3, pp. 219-230, 1999.

[31] G. Liu and L. Yan, "A study on numerical integration in elementfree methods," in Proceedings of the 4th Asia-Pacific conference on computational mechanics, pp. 979-984, Singapore, 1999. 


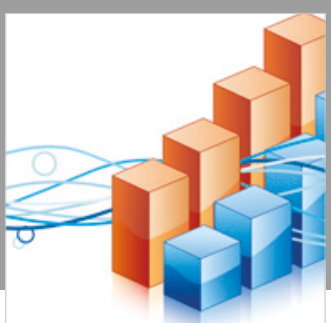

Advances in

Operations Research

\section{-n-m}
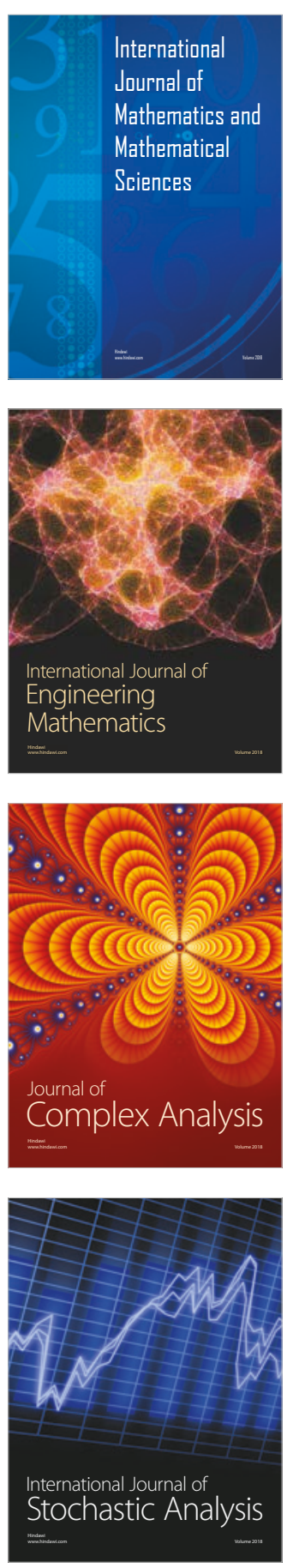
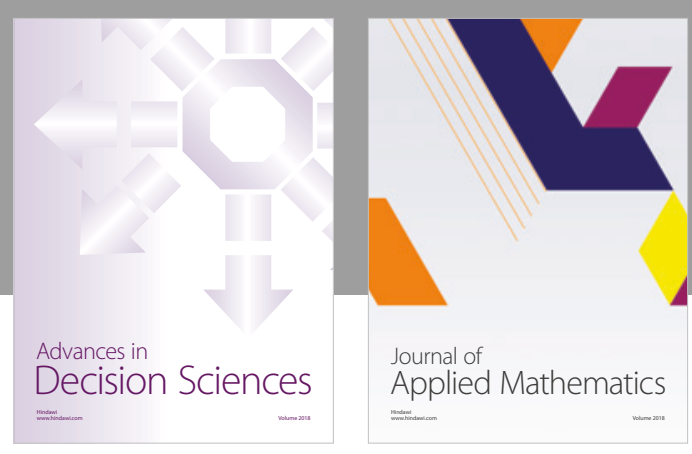

Journal of

Applied Mathematics
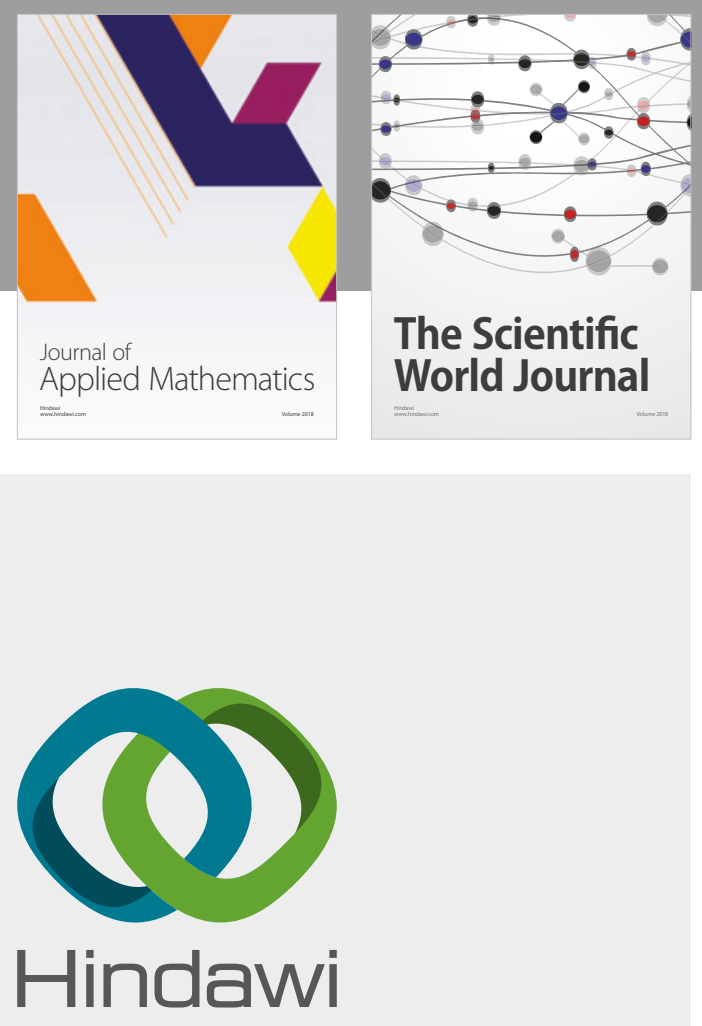

Submit your manuscripts at

www.hindawi.com

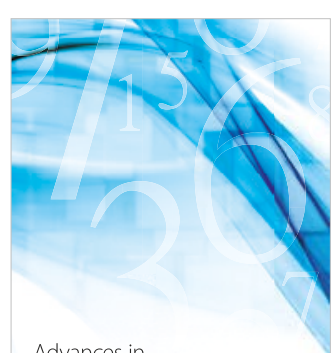

Advances in
Numerical Analysis
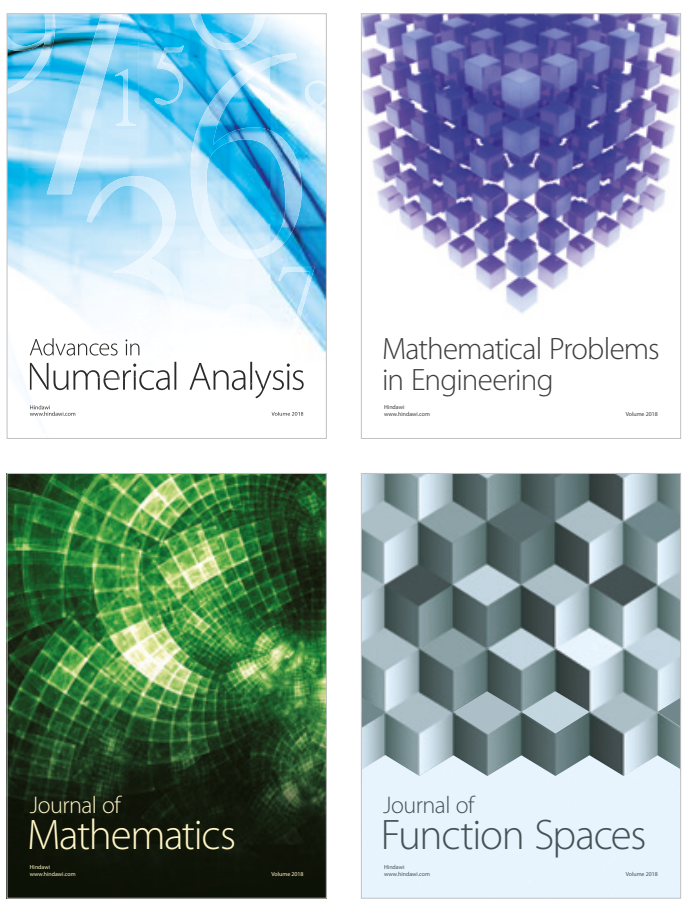

Mathematical Problems in Engineering

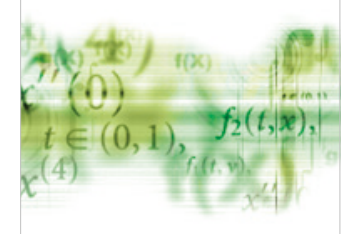

International Journal of

Differential Equations

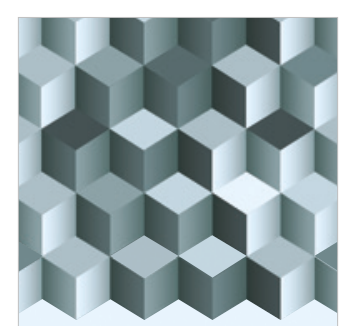

Journal of

Function Spaces

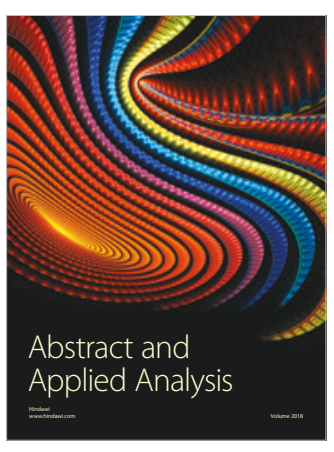

The Scientific

World Journal

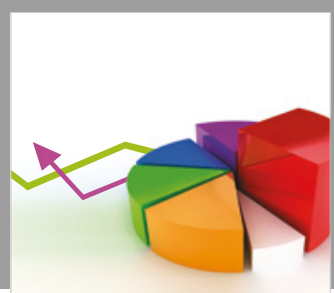

Journal of

Probability and Statistics
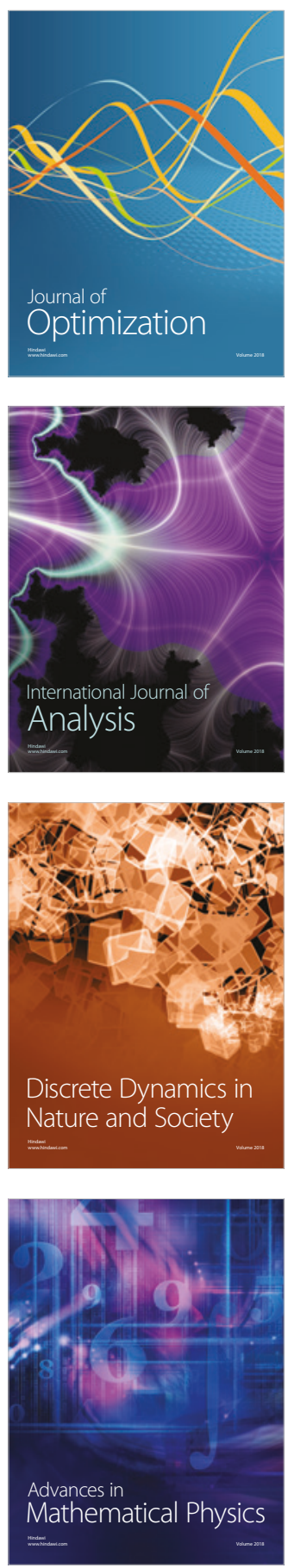